\title{
"BUILDING PERMITS" AS PROOF OF CONCEPTS IN MERGING GIS AND BIM INFORMATION: A CASE STUDY
}

\author{
ERLING ONSTEIN $^{1} \&$ MATIAS GONZALEZ TOGNONI ${ }^{2}$ \\ ${ }^{1}$ Department of Manufacturing and Civil Engineering, Norwegian University of Science and Technology, Norway \\ ${ }^{2}$ Arkitektum AS, Norway
}

\begin{abstract}
The information content in a Building Permit Application includes a BIM part (documentation of selected parts of a planned building) and a GIS part (its consequences for the neighbours and impact for neighbourhood/society). The work with this case have several steps: overall model mapping, content requirement and filter rule definitions, feature instance mapping and automated quality check in every step. Our finding is hopefully useful also for others. The principles for mapping between GIS and BIM have been investigated. The national spatial infrastructure in Norway is based on the ISO19100 family of standards, where the General Feature Model as defined in ISO19109 is of special relevance. On the BIM side, ISO16739 IFC is important. The paper compares these two, and presents a list of similarities and differences, relevant for the case. Filtering information from the IFC dataset has always been important for the BIM society. The relevant building permit requirements is mapped into contents requirements and filtering rules using BIM-supported "encoding languages" (mvdXML and simpleBIM template). Mapping the GIS information over to IFC encoding has been investigated. Some challenges are discovered and possible solutions are described.
\end{abstract}

Keywords: GIS to BIM, spatial information, conceptual modelling, information requirements, validation.

\section{INTRODUCTION}

The BIM-GIS integration is currently an important research activity. Examples of activities focusing the data part, as building unified GIS/BIM-models for 3D urban GIS [1], solving computational challenges for BIM-models [2], and integration of detailed BIM-data with powerful GIS analysis tools [3], all bring valuable experiences for parts of the BIM-GIS integration challenge. In BIM, project development and handling different project stages is also important, see [4].

Open Geospatial Consortium (OGC) and buildingSMART International (bSI) have worked together for some time to create a framework to integrate the build environment across domains and different aspects of use. A white paper is announced to be published after a joint November 2016 workshop [5].

ISO/TC211 Geographic information/Geomatics initiated 2016 a standardisation project on BIM to GIS conceptual mapping. ISO/TC211 consider this as a first of several standards needed bringing GIS and BIM closer together.

The activities described in this paper are part of project KS eByggesak, a project for defining requirements for software handling building applications, run by The Norwegian Association of Local and Regional Authorities (KS). KS eByggesak is planning to have several testbeds to spread knowledge of using BIM/IFC in building applications, how to use GIS datasets in BIM software in the planning phase, validating IFC dataset against exchange requirement for building permits and using IFC to update central databases as the central cadaster registry. 


\subsection{General introduction to Building Permit Applications (BPAs)}

A Building Permit Application (BPA) is an application where people apply for public permission to build a building. There are common regulations on national level describing both the technical requirements to the buildings [6], and also requirements to the application [7]. The application must ensure that the interest of all involved parties are taken into account: the builder, the neighbours and the society. In a BPA the technical requirements are due to builders own declaration, and checking this is not part of the BPA itself. More easy ways of including technical documentation in a BPA, will be useful for builders claiming to fulfil the requirements. Given national regulations and local application handling, there will be possibilities for local preferences in BPA handling.

In typical BIM projects, the deliverables from one project stage to another are to some degree depending on project agreement. BPA can be considered as one stage in a project, but the requirements to the BPA deliverables are mainly defined by public authorities. Thus, experiences with BPA will be valid for most BIM projects.

\subsection{Our goal: adding neighbourhood information to other IFC parts}

In BIM projects, it is common that the actors (e.g. architects, civil engineer consultants) produce their own IFC dataset for their parts of the project. The datasets are then put together for collision tests and other quality checks. The idea for this BPA project is to encode the neighbourhood using IFC, holding information on e.g. areal plans, roads, property parcels and water systems. The neighbourhood IFC data, with its origins in GIS, could be the main source for spatial reference system used in the project.

This is, as far as we have seen, not a usual way of working. Available IFC viewers have challenges showing such neighbourhood files. Autodesk Revit, has at least in Norwegian plugins, functionality for reading neighbourhood information from "native GIS formats" into Revit projects. Tekla in their Tekla BIMSight uses IFC data for building parts, but Sketchup data for terrain.

IFC have some possibilities to encode neighbourhoods. In the following, selected challenges are further described.

We have only worked with a one-way-transformation from the GIS side to the BIM side. This imply that we still rely on full maintenance, management and updating of the original GIS-data on some GIS platform.

\subsection{Content of this paper}

After the introduction in the first section, the paper describes the challenges on conceptual mapping (section 2), presents selected challenges connected to neighbourhood data (section 3), on filtering/validation of BIM data (section 4) and on mapping GIS feature instances from GIS to BIM (section 5). The paper ends with conclusions and recommendations for future work in section 6 .

\section{COMPARING BIM AND GIS AT THE CONCEPTUAL LEVEL}

In the work with transferring information from GIS to BIM, some overall challenges connected to conceptual modelling must be taken into account. 


\subsection{Differences in modelling level and languages}

One challenge when comparing GIS and BIM, is selecting the suitable level of modelling. The main principles in GIS modelling are found in the ISO19100-family of standards, of special interest is the General Feature Model (GFM) as defined in ISO19109. This is, as the name tells, a general model. It is described in the standard as part of the rules for making user application schemas. The ISO19100 family of standards does not define any application schemas, only rules for how users should define their own. CityGML [8] is often picked as the GIS-side application schema, with use case rather close to BIM. But CityGML is just one out of a lot of possible GIS application schema.

On the BIM side, the main content of the IFC standard [9] is the standardized BIM application schema.

A second challenge for the comparison is the two different conceptual modelling languages used; Unified Modelling Language (UML) and STEP/EXPRESS (ISO10303-11). A full discussion on similarities and differences in the two languages is out of scope for this paper. However, the discussed differences in the following sections to some degree are connected to the differences in the modelling language.

\subsection{Terminology challenges: models, feature types and entities}

In GIS, the term model is mainly connected to the schema level, i.e. definition of conceptual models and applications schemas. In BIM, a model is supposed to be more on the instance level, describing one specific building. In this paper, model is used in the GIS way.

GFM define feature type as the term for a class representing a set of real world instances sharing common properties. The user application schemas contain user-defined feature types. EXPRESS and thus IFC uses entity for similar semantics. In this paper both terms (feature types and entities) are used.

\subsection{The quality aspect}

The main data capture goal for GIS is to produce a digital representation of the real world. The main quality issue is how well the digital representation describes the real world, see [10]. In the BIM case, the situation is somehow turned around, as the model containing builders needs and selected solutions, is the "ground truth", and the as-build-documentation describes whether the details of the build building are within acceptable tolerances or not. However, if the "resulting building" is accepted, then the physical building becomes the ground truth, and the situation is as in GIS.

\subsection{Object and type objects}

In BIM, several object instances are supposed to be produced according to the same specification. Common properties for the object instances are connected to the type object. Only individual differences (e.g. local placement) are connected to the object instances.

In GIS type objects is not used. The one who made the "GIS real world" did not buy anything from any component producer, all instances are unique. The feature instances are classified into feature types. All the feature instance properties are connected to the feature instance. 


\subsection{Spatial reference systems}

One main principle in all GIS data, is to use global coordinate reference system (CRS) for all given positions. As GIS data is supposed to be related to the earth, the used global CRSs must refer to the earth. Horizontal and vertical positions need separate CRSs, with different mappings from CRS-distances to real-world distances. Due to the earths shape and the wish to have homogeneous CRSs over as wide area as possible, all horizontal global CRSs imply a distortion. This distortion must be taken into account when calculating real world distances and directions from representations. Vertical CRSs usually have no scale distortion, only different zero point. The principles in the EPSG registry [11], the common global registry for CRSs, makes it possible to define compound CRSs, i.e. allocate an own EPSG registry unit for the combination of one horizontal and one vertical.

In BIM data it is essential to have positions that give real world distances in all three dimensions direct from coordinate (Pythagoras) calculations. Ifc4 added IfcProjectedCRS together with additional IFC entities to define global CRSs in IFC data. Unfortunately, there is only very loose IFC model defined semantic connection between the name of a IfcProjectedCRS and the spatial properties given in e.g. the EPSG registry. The IFC elements for CRS still misses the separation/combination of horizontal and vertical CRS.

In IFC data, the last millimetres are usually important. Keeping the millimetre precision in what at least theoretical can be inhomogeneous horizontal and vertical CRSs, require real professional users.

In GIS information, all positions are in same CRS. In most of the GIS transfer file formats, with GML as an exception, the identification of the spatial reference system is found in the dataset header. In BIM information it is common that every object instance has its own local placement point and a rotation, and most of the geometry connected to the object instance are local positions, relative to the object instance local placement. Sets of rotation matrixes and "offset points" in $\mathrm{x}, \mathrm{y}$ and $\mathrm{z}$ are needed to transform the local coordinates to a common project CRS.

\subsection{Attribute handling}

In GFM it is required that all user defined feature types in the user application schemas have their own specific set of mandatory and optional properties. This seems reasonable, since the goal of GFM is to guide users to define their own application schema.

The role of IFC is to be the universal application schema. Then there is a need for another "strategy" for satisfying user needs. In IFC a set of entities are defined. IFC also defines a lot of properties, and group them into property sets. The predefined entities have a list of recommended property sets. But users may add more property sets. There is no direct relationship between entity and property sets. An "objectified relationship" IfcRelDefinesByProperies, is used as connection table to connect object instances and instances of property sets. This makes IFC more flexible and also more challenging than GFM-based data.

\section{NEIGHBOURHOODS IN IFC}

IFC is mainly an application schema for parts of and components connected to buildings. One main part of a BPA is how the building will influence on the neighbourhood. The data needed for making decisions on the influence, must have information related to the neighbourhood of the building. 
Neighbourhood is also of interest in the design phase of a new building, making it possible for the architects to consider the environment of the planned building.

In our project we have investigated the possibilities of encoding both the planned building and the neighbourhood using IFC. Encoding all the relevant information into one single dataset would make it easy for the authorities to keep the needed information together for documentation and archiving purposes.

In our project, we have considered several types of neighbouring objects:

- Neighbouring buildings. This is buildings close to the new building.

- Areal plan. One important question in a BPA, is whether the project is in accordance with the public areal plan for the area.

- Parcels. This is information on property parcels and parcel boundaries.

- Infrastructure, i.e. roads and utilities.

- Water system.

For representing neighbourhoods in IFC, suitable entities are needed. In addition, a grouping structure for the entities is needed.

\subsection{On the IFC entity to be used}

Neighbouring buildings is supposed just to be shown as "geometry boxes" possibly added by some selected information from public building registers. This can be done by using IfcBuilding with just a representation solid geometry. No further building details (IfcBuildingElements) are needed. Such a building can alternatively be represented as instance of IfcGeographicElement.

For existing roads, also several options exist. The IFC model has an entity IfcCivilElement, explained as "a generalization of all elements within a civil engineering works" [9]. Common understanding of civil engineering includes buildings. However, it might seem like this IFC entity is mainly intended as a place holder for future IFC extensions into road and utility construction projects, not for representing buildings (already covered by IfcBuildingElement) and existing GIS objects.

The entity IfcGeographicElement also seems as an alternative for existing objects, including roads.

\subsection{Classification of objects}

In traditional IFC data, properties for object instances are represented either in the object instance or on the related type object instance. This "type object mechanism" can also be used for classification of neighbourhood features, e.g. by relating all object entities representing roads to the same object type instance. Alternatively, the semantic parts of the object instance information can also be stored in proper object instance properties, e.g. name or description.

\subsection{Structuring of entities into hierarchy using relationship entities}

In a GIS dataset, the feature instances belonging to one data set are just loosely connected. In Ifc, the object instances must, in addition to be classified using a predefined IFC entity, also belong to a structure. The IFC structure is shown in. The common used structure elements used for buildings and building components are shown in green. Candidate structure elements for neighbourhood entities are shown in the bottom line in white. Unfortunately, reading the IFC documentation give no clear understanding on which one to select. 


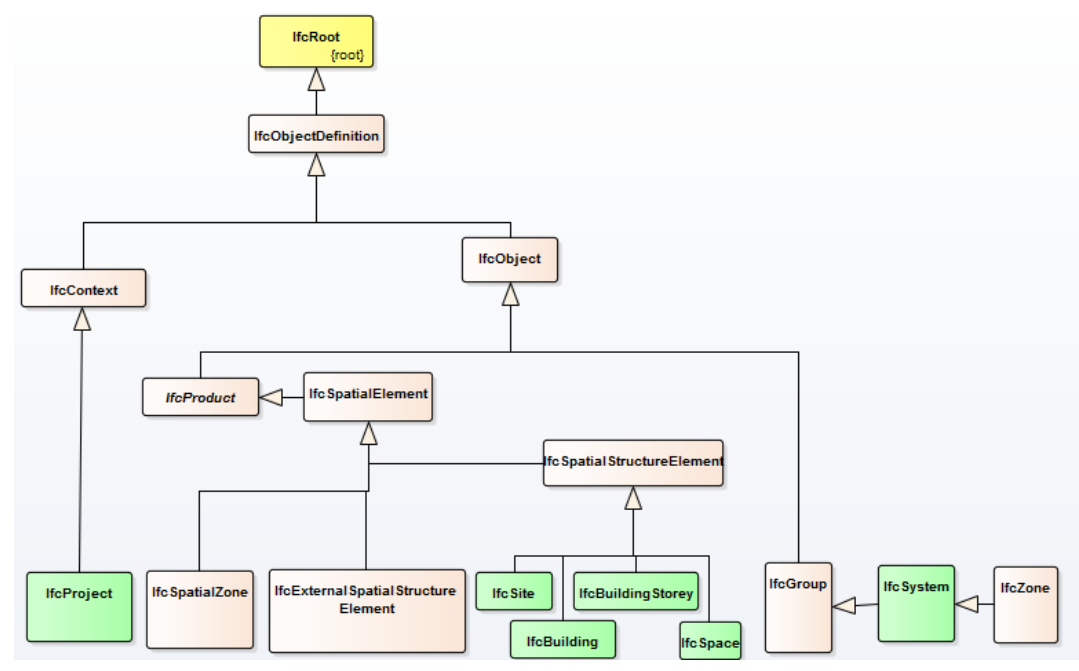

Figure 1: IFC structure elements (shown in UML Class diagram).

A set of relationship entities are defined for connecting entity instances to structure elements. It is not easy to read from the IFC documentation which elements that should be connected to which structure elements using which relationship elements.

\subsection{Selected IFC data structure related to neighbourhoods}

In lack of clear advice and experiences, we used the following as structure elements for the neighbourhood IFC dataset:

- IfcProject: The logical root of an IFC file. In a building project, the involved actors will produce their own IFC file for their content. The actors have limited IFC support of referring to one common IfcProject for such a set of IFC files.

- IfcSite: Each IfcProject may have several IfcSites. In our case, we used only one IfcSite for each IFC file. Ifc4 defines IfcSite as "a defined area of land...on which the project construction is to be completed" [9]. In, the extent of the IfcSite is shown in green, surrounded by neighbourhood areas.

- IfcSpatialStructureElement subtypes (see ) is used "to provide a project structure to organize a building project" [9]. Each IfcSite may have IfcBuildings, possibly also IfcBuildingStoreys and IfcSpaces. Our understanding is that this is mainly for parts of the building under construction.

- IfcSpatialZone is "a potentially overlapping decomposition of the project under some functional consideration." [9].

For IfcBuildings, only "the main building" is supposed to have building elements. We defined IfcSpatialZones containing collections of IfcGeographicElements for water drainage system and parcel. Areal plans could also have been handled in similar way. We have used entity IfcCivilElement for neighbouring buildings and existing roads. shows one resulting IFC dataset using this structure. 


\subsection{Experiences}

The extensions needed for handling neighbourhoods are introduced in Ifc4. However, the explanations in the standard are not complete and seems to need further explanations. This lack of clear descriptions is also supposed to be one of the main reasons for the lack of support for neighbourhood information in available IFC viewers.

\section{FILTERING AND RULE CHECKING IN BIM AND GIS}

We have three main goals for the project parts regarding filtering and rule checking:

- An open, formal language for definition of filtering and rules

- Authoritative software support

- User-understandable error messages

Spring 2016 three students from NTNU in Gjøvik made a prototype (see [12] and section 4.2). They selected simpleBIM [13] as language and software, mainly because of missing alternatives, and high score on understandable error messages.

buildingSMARTInternational works with mvdXML [14] as the preferred language for model views. IfcDoc is a software reading IFC documentation, with functionality to build the rules from the IFC $2 \times 3 / 4$ schemas. IfcDoc have also the ability to export the selected schema parts and defined rules to mvdXML. The open source software xBIMExplorer seems promising for combining IFC data with mvdXML-rules. However, is seems still to be some steps to go to compete simpleBIM, at least on the aspect on user understandable error messages.

\subsection{Model views using mvdXML}

In the project we also have tried to transfer the BPA-rules from simpleBIM-encoding to mvdXML (see Fig. 2). Until today, it seems like the mvdXML-specification is still under development, and implementations suffer from the immature specifications.

\subsection{Prototype spring 2016}

Egeli et al. [12] have produced a prototype for filtering and validation of IFC data for BPA. They demonstrated how an early version of an MsExcel-based Exchange Requirement (ER) can be implemented. The implementation needed a structured way of representing the filtering and validation in the ER document, and a user-friendly interface for presenting results. This they found in simpleBIM from DataCubist Oy.

Fig. 3 shows how the content of a IFC file is divided into three parts (included, excluded and not decided), and how selected attribute and attribute values are validated. An instructive "Not allowed" symbol is used where validation rules are broken.

They point in their project on the importance of open and commonly accepted format for rules and validation. They started out with the mvdXML as the format. However, they did not found mvdXML and mvdXML supporting software mature enough for their work.

5 INSTANCE MAPPING: DERIVING IFC DATA FROM 2.5D GIS DATA In Norway, the FKB specifications for buildings [15] are used when capturing data for base data sets. The specifications describe a " $2.5 \mathrm{D}$ world", where the objects visible in the aerial photos are mapped to lines using sequences of xyz-points. The terrain surface is represented 


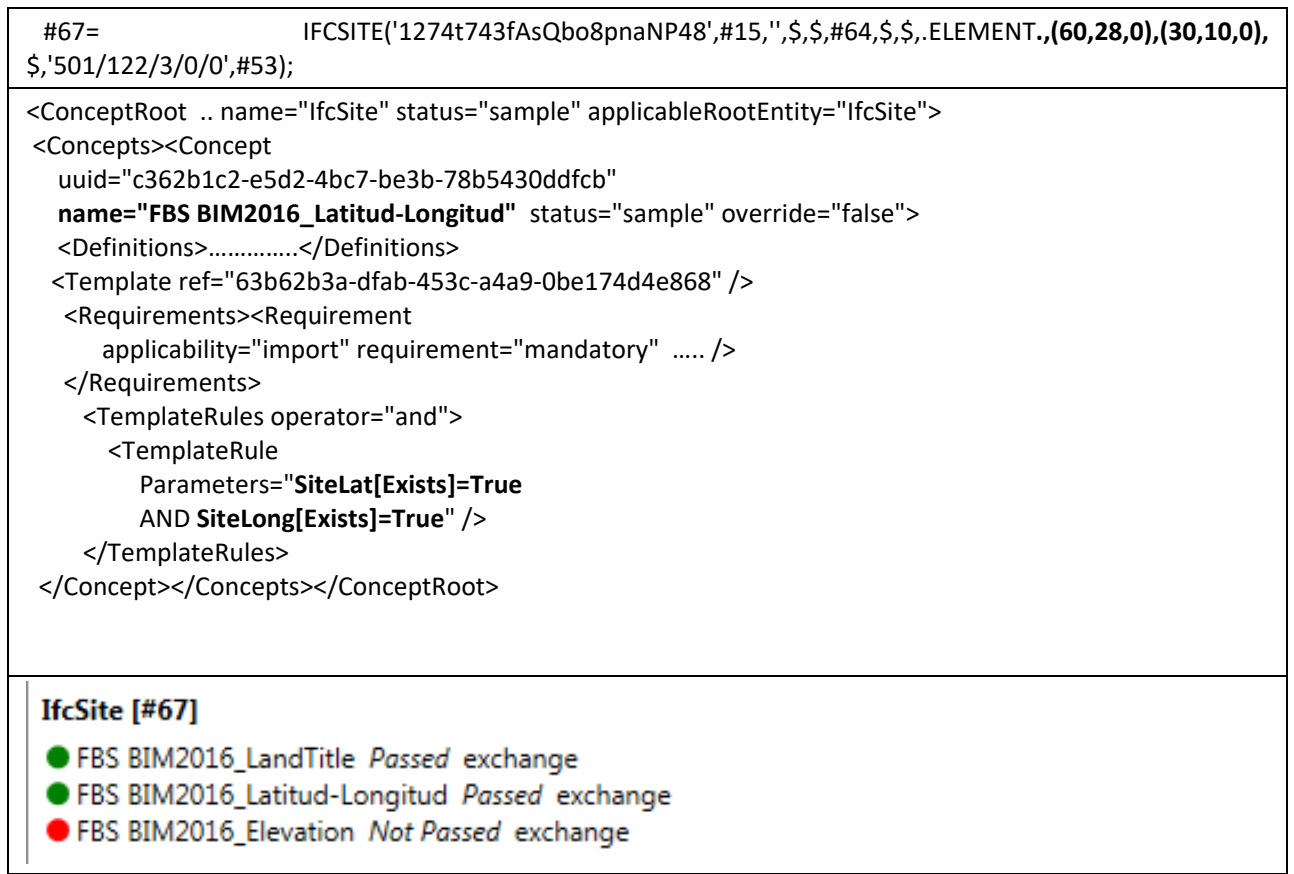

Figure 2: Example on mvdXML. Top: IFC data; middle: mvdXML-rule; Bottom: xBIMExplorer error message.

mainly as contour lines. Area features as areal plans, road systems, water system are mapped as polygons, i.e. only bounding geometry for the areas. Buildings are represented as a set of lines representing characteristic lines of the building (see Fig. 4), where pink lines show what is photogrammetrically registered.

We have used FME from Safe Software [16] to convert FKB-based 2.5D data info IFC:

- Generating TIN-based site surface from contour lines. This is a rather well-known task, working quite strait forward, using contour lines and selected break lines as input data.

- Generating IfcSurfaces for "neighbouring polygon-based areas". For this task, we used FME draping tool followed by clipping tools for filling the polygons with TIN surfaces.

- Generating IfcSolids for IfcBuildings based on 2.5D building lines is the really challenging part of the job, and more research is needed to have a suitable solution. Fig. 5 shows some of the remaining challenges for making closed 3D solids.

\subsection{Viewing and validation of IFC result}

Our primary goal when producing the IFC representation, was to use semantic understandable entities and structure elements. To be able to have "nice views" using available IFC viewers, some "secondary goals" were needed. We decided, in spite of the "nature" of the entities, to use solid geometries for surface objects such as roads. Two 
Building Information Modelling (BIM) in Design, Construction and Operations II 163

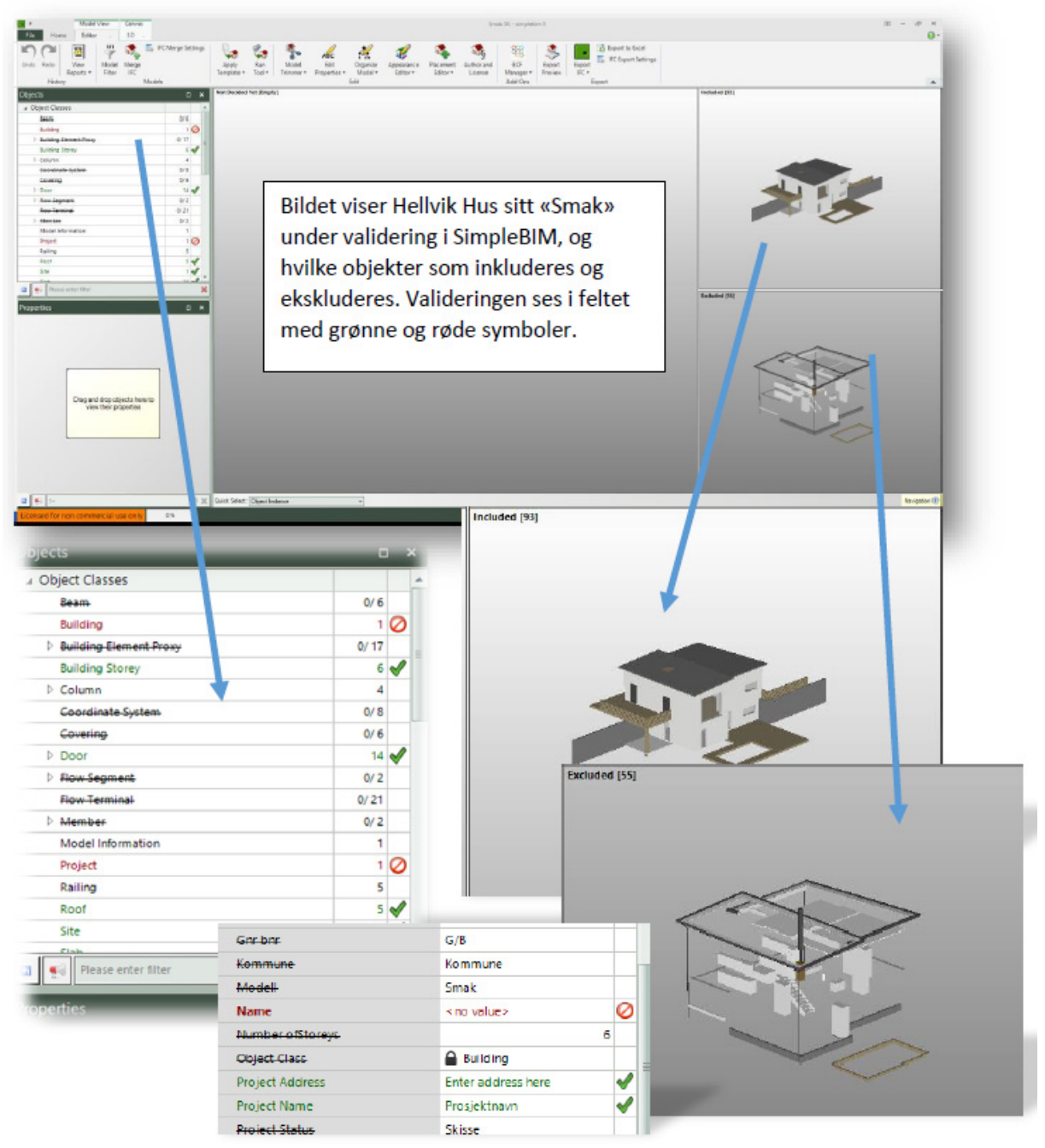

Figure 3: IfcModel validation using simpleBIM. (Source: [12].)

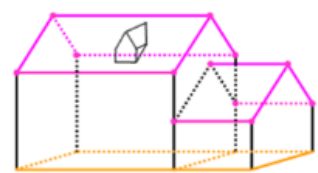

Data capture (pink)

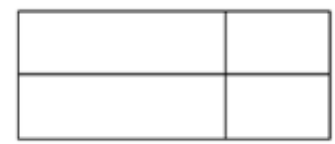

Map presentation

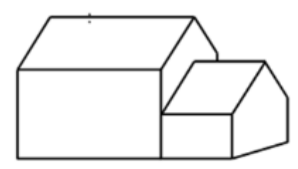

3D Solid

Figure 4: FKB-B specification building parts. (Source: [15].) 


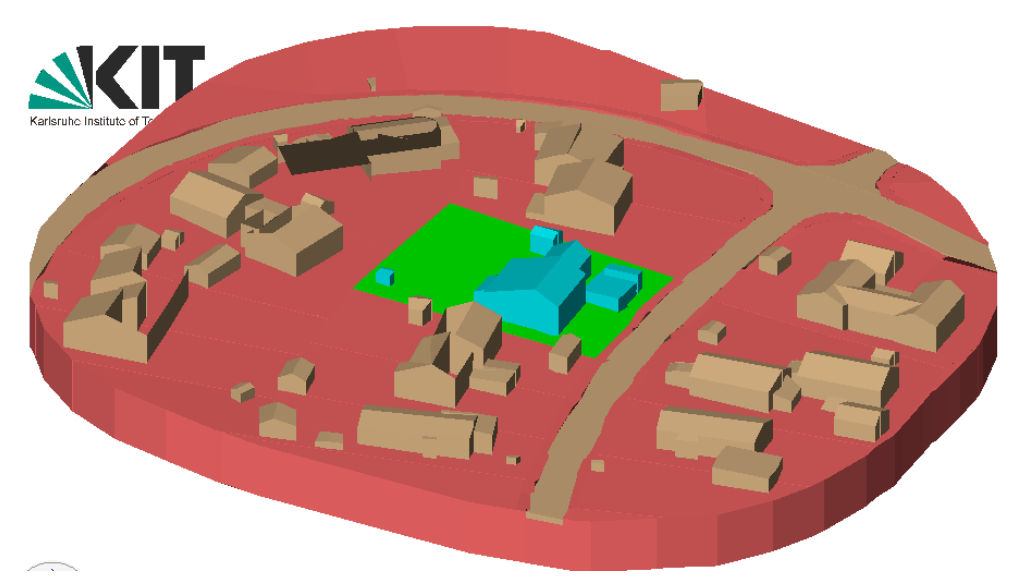

Figure 5: IFC representation with neighbourhoods for KS test bed using FZKViewer.

surfaces in the same data set will not be shown as a nice picture, as the surfaces are not identical, which one is on top will vary from spot to spot. The available viewers also have limited functionality for selecting which objects should be on top and which should be hidden down under. One view of the IFC result is found in .

There is also a need for a pure "IFC validator" to give "the final judging" of a IFC file. Commercial IFC viewers have implemented limited functionality for meeting user needs. None of the used commercial IFC viewers we have used have a pure "check the file against the standard"-functionality. The FZKViewer [17] has one IFCValidator implemented. This validator seems to have a deep check of geometries, but not necessarily a similar level of checking file structure, and the use of IFC structure elements.

\section{CONCLUSIONS}

From the activities described above, some conclusions can be drawn:

- IFC can be used as representation format for the needed information related to BPA. However, as alternative solutions for merging GIS and BIM data is not investigated in this project, we have no conclusion whether this should be the preferred way of working.

- A common understanding in the BIM community of the semantics of the new possibilities for encoding of neighbourhoods introduced in Ifc4 is needed to ensure consistent implementations.

- mvdXML seems suitable for filtering and validation of IFC data. A more stable/mature/authoritative version is needed.

- Need for a more authoritative IFC Validator, also checking the structure of the information.

- Handling of global coordinate reference systems is added to the Ifc4. However, to handle the full extent of global CRSs as done in GIS, more specifications is needed in Ifc4.

Two topics seems to be of special importance for future work: 
- Computer-based filtering and validation of data. More experiences, e.g. on the use of the maturing mvdXML standard, is needed to be able to take further steps in automation/digitizing in the BIM/GIS area.

- Differences in geometry representation in GIS and BIM, including use of global CRSs. Although not treated in this paper, it seems like this might be one main obstacle for shuffling data back and forth between GIS and BIM.

\section{ACKNOWLEDGEMENT}

This project was partly funded by The Norwegian Association of Local and Regional Authorities (KS), under the project Plan, bygg og geodata/eByggesak.

\section{REFERENCES}

[1] El-Mekawy, M., Östman, A. \& Hijazi, I., A unified building model for 3D urban GIS. ISPRS International Journal of Geo-Information, 2012.

[2] Kim, J.E., Hong, C.H. \& Son, S.D., A light weight algorithm for large-scale BIM data for visualization on a web-based GIS platform. Building Information Modelling (BIM) in Design, Construction and Operations, eds L. Mahdjoubi et al., WIT Press, 2015.

[3] Boguslawski, P., Mahdjoubi, L. \& Zverovich, V., BIM-GIS modelling in support of emergency response application. Building Information Modelling (BIM) in Design, Construction and Operations, eds L. Mahdjoubi et al., WIT Press, 2015.

[4] Mejlænder-Larsen, Ø., Using BIM to follow up milestones in a project plan during the design phase. Building Information Modelling (BIM) in Design, Construction and Operations, eds L. Mahdjoubi et al., WIT Press, 2015.

[5] buildingSMARTInternational, Geospatial and build asset collaboration, 2016. http://buildingsmart.org/geospatial-built-asset-collaboration/. Accessed on 3 Dec. 2016.

[6] Norwegian Building Authority (Dibk), Regulations on technical requirements for building works, 2010. https://dibk.no/globalassets/byggeregler/regulations_on_ technical_requirements_for_building_works.pdf

[7] Norwegian Building Authority (Dibk), Regulations relating to building applications, 2010. https://dibk.no/globalassets/byggeregler/building_application_regulations.pdf

[8] Open Geospatial Consortium, OGC City Geographical Markup language (CitiGML) Encoding Standard, 2012. http://www.opengeospatial.org/standards/citygml

[9] buildingSMARTInternational, IFC4 Add 2 (ISO16739), 2016. http://www.building smart-tech.org/ifc/IFC4/Add2/html/. Accessed on 3 Dec. 2016.

[10] International Organisation for Standardization, ISO 19157 Geographic Information Data Quality, 2013.

[11] International Association of Oil and Gas Producers, About the EPSG dataset, 2016. http://www.epsg.org/. Accessed on 3 Dec. 2016.

[12] Egeli, K., Røstadli, S. \& Werner, S., Implementering av BIM i kommunal forvaltning for effektiv, likebehandlet og kvalitetssikret byggesaksbehandling (Norwegian), Student project, One Year BIM Study, NTNU, 2016.

[13] DataCubist Oy, simpleBIM, 2016. http://www.datacubist.com/. Accessed on 3 Dec. 2016.

[14] buildingSMARTInternational, mvdXML 1.1, 2016. http://www.buildingsmart-tech. org/ifc/IFC4/Add2/html/. Accessed on 3 Dec. 2016.

[15] Statens Kartverk, FKB Bygning 4.02 (in Norwegian), 2013. http://sosi.geonorge.no/Produktspesifikasjoner/FKB/5-bygning-2013-01-01.pdf. Accessed on 3 Dec. 2016. 
166 Building Information Modelling (BIM) in Design, Construction and Operations II

[16] Safe Software, FME Desktop, 2016. http://www.safe.com/fme/fme-desktop/. Accessed on 3 Dec. 2016.

[17] Karlsruhe Institute für Technologie, Institute für Angewandte Informatik, FZK viewer, 2016. http://iai-typo3.iai.fzk.de/www-extern/index.php?id=1931. Accessed on $3 \mathrm{Dec}$. 2016. 